\title{
The Servant Leadership Survey: Development and Validation of a Multidimensional Measure
}

\author{
Dirk van Dierendonck • Inge Nuijten
}

Published online: 3 September 2010

(c) The Author(s) 2010. This article is published with open access at Springerlink.com

\begin{abstract}
Purpose The purpose of this paper is to describe the development and validation of a multi-dimensional instrument to measure servant leadership.

Design/Methodology/Approach Based on an extensive literature review and expert judgment, 99 items were formulated. In three steps, using eight samples totaling 1571 persons from The Netherlands and the UK with a diverse occupational background, a combined exploratory and confirmatory factor analysis approach was used. This was followed by an analysis of the criterion-related validity.

Findings The final result is an eight-dimensional measure of 30 items: the eight dimensions being: standing back, forgiveness, courage, empowerment, accountability, authenticity, humility, and stewardship. The internal consistency of the subscales is good. The results show that the Servant Leadership Survey (SLS) has convergent validity with other leadership measures, and also adds unique elements to the leadership field. Evidence for criterion-related validity came from studies relating the eight dimensions to well-being and performance.

Implications With this survey, a valid and reliable instrument to measure the essential elements of servant leadership has been introduced.

Originality/Value The SLS is the first measure where the underlying factor structure was developed and confirmed across several field studies in two countries. It can be used in future studies to test the underlying premises of servant leadership theory. The SLS provides a clear picture of the
\end{abstract}

D. van Dierendonck $(\square) \cdot$ I. Nuijten

Rotterdam School of Management, Erasmus University,

Erasmus University Rotterdam, PO Box 1738, Room T08-07,

3000 DR Rotterdam, The Netherlands

e-mail: DvanDierendonck@rsm.nl key servant leadership qualities and shows where improvements can be made on the individual and organizational level; as such, it may also offer a valuable starting point for training and leadership development.

Keywords Servant leadership · Measurement development - Positive organizational behavior . Empowerment · Humility

The 21st century has launched a rocketing interest in leadership theories. The emphasis has shifted to enhancing motivation and social responsibility to secure success and profit in modern organizations. Leadership has been suggested to be a key factor for engaged employees (Luthans 2002) and for innovative organizations (Garcia-Morales et al. 2008). The present theory of servant leadership may be of great value in this respect. Servant leadership was first introduced by Greenleaf (1977) more than 30 years ago, and has recently been rediscovered by scholars. It is characterized as a more ethical (Clegg et al. 2007) and people-centered theory of leadership. Compared to transformational leadership, it introduces a moral component (Graham 1991), and puts explicit emphasis on the needs of followers (Patterson 2003). In servant leadership the ideal of service is embedded in the leader-follower relationship. The biggest difference with other types of leadership is that servant leaders are genuinely concerned with followers (Greenleaf 1977), rather than-for example with transformational leaders-organizational objectives (Graham 1991; Stone et al. 2004); that they work from a base of equality combined with a strong focus on social responsibility (Reinke 2004).

The aim of this article is to describe the development of a valid and reliable instrument that measures servant leadership in all its complexity, that is behaviorally 
oriented, focuses on the role of the leader in the relationship with followers, and which is easy to use. Despite previous attempts to construct a valid and reliable instrument, there still is a need for a concise scale representing the essential characteristics of servant leadership within a multi-dimensional framework directly linked to Greenleaf's ideas. At the moment, there is no generally agreed upon definition of what servant leadership is in terms of leader behavior. That is an important reason why different measures exist. It should be acknowledged that no single measure can fully capture and operationalise complicated constructs-like servant leadership — and that it may be sensible to have a broader range of instruments available (Leary and Hoyle 2009). This is particularly true for servant leadership. We need studies comparing the different measures to enhance our insight into what the core of servant leadership is. An instrument of servant leadership would ideally (a) be very valuable in encouraging empirical research to understand the real value of servant leadership within modern organizations, (b) help to understand which dimensions are critical for employee well-being and performance, and (c) help to determine how servant leadership differs from other leadership styles, such as transformational and ethical leadership. We will first describe the foundations of our theoretical model on which we based the item formulation. Next, the psychometric analyses, including exploratory and confirmatory factor analyses, will be discussed. Finally, the content, incremental and criterion-related validity is addressed.

\section{Phase 1: Development of the Servant Leadership Survey}

In his seminal work "The Servant as Leader", Greenleaf (1977) introduced his basic ideas on servant leadership. This booklet did not give a concise conceptual definition of servant leadership. According to Greenleaf 'going beyond one's self-interest' was the core characteristic of servant leadership; although mentioned in other leadership theories, it has never been given a central position as in servant leadership theory. The servant leader is governed by creating opportunities for followers to help them grow (Luthans and Avolio 2003). It is also important to realize that according to Greenleaf the servant leader is 'primus inter pares' (i.e., first among equals). Servant leaders do not use their power to get things done, but use persuasion to convince their staff. In addition, and more explicitly than in any other leadership theory, servant leadership theory places the leader in the role of a steward who holds the organization in trust (Reinke 2004). Recently, Parolini et al. (2009) confirmed that, when comparing them to transformational leaders, servant leaders are perceived as more focused on the needs of the individual; their allegiance lies more with the individual than with the organization; quite contrary thus to transformational leaders. Based on Greenleaf's ideas, Spears (1995) distinguished 10 characteristics that are generally quoted as the essential elements of servant leadership: listening, empathy, healing, awareness, persuasion, conceptualization, foresight, stewardship, commitment, and building community.

The development of an adequate instrument requires that several criteria have to be met. Primarily, the multi-dimensionality of the concept should be guaranteed. Servant leadership covers a wide range of behaviors which are hard to grasp in one or two constructs, and may sometimes seem difficult to disentangle. In addition to Spears (1995), several other scholars have been engaged in servant leadership behavior. Laub (1999), for example, developed a conceptual model of six clusters of servant leadership characteristics (personal development, valuing people, building community, displaying authenticity, providing leadership, sharing leadership), each consisting of three categories. Russell and Stone (2002) mentioned nine functional characteristics (vision, honesty, integrity, trust, service, modeling, pioneering, appreciation of others, empowerment) and eleven additional characteristics of servant leadership. Finally, Patterson's (2003) model includes seven dimensions (agapao love, humility, altruism, vision, trust, empowerment, service).

It seems that from a theoretical point of view, one is inclined to include dozens of characteristics a leader needs to display to be called a servant leader which are in turn hard to include in a methodological design, and may be hard to handle in practice. This has indeed proved to be a real challenge. Earlier servant leadership research showed quite some content overlap in the operationalisation of the different dimensions underlying the proposed measure. For instance, Laub (1999) developed a 60-item measure - the Organizational Leadership Assessment (OLA)—clustering six key areas. Although the OLA should be credited for stimulating servant leadership research, the intercorrelations between the six areas are so high that the overall OLA score is recommended for research purposes, whereby its multidimensional nature is lost. Another frequently used instrument is Page and Wong's (2000) Servant Leadership Profile. Building from a 12 dimensional conceptual framework, they initially distinguished eight dimensions; and later reduced them via seven to five (Wong and Davey 2007). In an attempt to replicate this factor structure, Dennis and Winston (2003) even brought it back to a threedimensional structure. Barbuto and Wheeler (2006) introduced a 23-item five-dimensional instrument that would match the 10 characteristics described by Spears. However, a recent attempt to replicate their findings failed and suggested that the instrument might actually be 
one-dimensional (Dannhauser and Boshoff 2007). Dennis and Bocarnea (2005) developed a five-dimensional instrument directly related to Patterson's (2003) seven-dimensional model. Unfortunately, their original study used one sample only. Recently, this instrument has been translated into Spanish and was studied within a Latin American context (McIntosh and Irving 2008) where the reliability for only three of the scales was confirmed.

A few years ago, Sendjaya et al. (2008) introduced an instrument consisting of 35 items representing 22 characteristics divided over six scales. Regretfully, their study does not provide information on the solidity of the hypothesized six-dimensional structure. The authors only tested the one-dimensionality of each of the six core dimensions separately. No data were presented on the factorial validity of the overall six-dimensional model. The intercorrelations between the dimensions ranged between .66 and .87 , which is a matter of concern for the proposed multi-dimensional structure. The only research where both an exploratory and a confirmatory sample were included is the one by Liden et al. (2008). They validated a 28-item seven-dimensional servant leadership scale in two samples, one consisting of 298 students, the other consisting of 182 individuals working for a production and distribution company. A confirmatory factor analysis confirmed their seven-factor model as the best fitting model.

Ideally, one would like to have a number of studies in order to reveal a multi-dimensional structure that holds across several samples. However, that is precisely what is missing. When used in other samples than the development one, constructs that were hypothesized to be separate constructs collapsed into one (e.g., Dannhauser and Boshoff 2007; Dennis and Winston 2003). Given these mostly unsuccessful attempts, it should not come as a surprise that Ehrhart (2004) used a one-dimensional selfdeveloped 14-item scale. However, a one-dimensional scale does not do justice to the concept of servant leadership.

Apart from the above mentioned problems, most - if not all-scales of servant leadership mainly deal with what we would call the 'people' side of servant leadership. This includes aspects like: helping, serving, being honorable, authentic, and empathic, behaving ethically, healing, and accepting. Although certainly valuable and important, they do not cover the whole concept. The use of the term 'servant' in servant leadership often results in too much attention for the people aspects of servant leadership. This can hinder its implementation in organizations. It is indeed important to pay equal attention to the 'leader' part of servant leadership. Servant leadership is also about giving direction. A servant leader knows very well where to take the organization and the people in it (Greenleaf 1977). A servant leader needs to be a courageous steward who is able to hold people accountable for their own good. In most of the scales these 'leader' aspects of servant leadership are missing. Liden et al. (2008) touch upon stewardship with their concepts 'creating value for the community' and 'conceptual skills', but ignore the important aspects of accountability and courage. The instrument we propose focuses on both the 'people' and the 'leader' aspects of servant leadership.

With the introduction of a new instrument-the Servant Leadership Survey (SLS)—we have attempted to overcome the above mentioned shortcomings. The SLS primarily focuses on the leader-follower relationship measured from the perspective of the follower. Our aim was that it should (1) cover the essential aspects of servant leadership, (2) be easy to apply, and (3) be psychometrically valid and reliable. We demonstrate the factorial validity, the internal consistency, the content validity, the incremental validity, and the criterion-related validity of this instrument in three phases.

Following Hinkin (1995), we conducted a study where a deductive phase was followed by an inductive phase given the importance of content validity with regard to the formulation of new items. After close reading of the available literature we summarized the main characteristics of servant leadership and formed a preliminary model of servant leadership (Van Dierendonck and Heeren 2006). Interviews were then held with managers who, according to experts from the European Greenleaf Centre for Servant Leadership, exemplified servant leadership. The insights from the literature as put forward in the preliminary model and those from these interviews led to the servant leadership characteristics, which we discuss below.

(1) Empowerment: a motivational concept focused on enabling people and encouraging personal development (Conger 2000). Empowerment aims at fostering a pro-active, self-confident attitude among followers and gives them a sense of personal power. Empowering leadership behavior includes aspects like encouraging self-directed decision making, information sharing, and coaching for innovative performance (Konczak et al. 2000). The servant leader's belief in the intrinsic value of each individual is the central issue in empowerment; it is all about recognition, acknowledgment, and the realization of each person's abilities and what the person can still learn (Greenleaf 1998).

(2) Accountability: holding people accountable for performance they can control (Conger 1989). This makes accountability a mechanism by which responsibility for outcomes is given to individuals and teams (Konczak et al. 2000). It ensures that people know what is expected of them, which is beneficial for both employees and the organization (Froiland et al. 1993). 
It is a powerful tool to show confidence in one's followers; it provides boundaries within which one is free to achieve one's goals. Although popular literature on servant leadership emphasizes accountability as very relevant, it has often been neglected by scholars and has never been incorporated in any of the other measures of servant leadership.

(3) Standing back: is about the extent to which a leader gives priority to the interest of others first and gives them the necessary support and credits. Standing back is also about retreating into the background when a task has successfully been accomplished. Standing back should be closely related to most other aspects of servant leadership such as authenticity, empowerment, humility, and stewardship.

(4) Humility: the ability to put one's own accomplishments and talents in a proper perspective (Patterson 2003). Humility in leadership focuses on daring to admit that one is not infallible and does make mistakes (Morris et al. 2005). Humility arises from a proper understanding of one's strong and weak points. Servant leaders acknowledge their limitations and therefore actively seek the contributions of others in order to overcome those limitations.

(5) Authenticity: is closely related to expressing the 'true self', expressing oneself in ways that are consistent with inner thoughts and feelings (Harter 2002). Authenticity is about being true to oneself, accurately representing_-privately and publicly_internal states, intentions, and commitments (Peterson and Seligman 2004). From an organizational perspective it can be defined as behaving in such a way that professional roles remain secondary to whom the individual is as a person (Halpin and Croft 1966).

(6) Courage: daring to take risks and trying out new approaches to old problems (Greenleaf 1991). According to Greenleaf (1991) courage is an important characteristic that distinguishes the servant leader from other leaders. Within the organizational context, courage is about challenging conventional models of working behaviors (Hernandez 2008); it is essential for innovation and creativity. Courage is related to pro-active behavior and implies creating new ways. To do so, means strongly relying on values and convictions that govern one's actions (Russell and Stone 2002).

(7) Interpersonal acceptance: the ability to understand and experience the feelings of others, understand where people come from (George 2000), and the ability to let go of perceived wrongdoings and not carry a grudge into other situations (McCullough et al. 2000). In other words, interpersonal acceptance is about empathy: being able to cognitively adopt the psychological perspective of other people and experience feelings of warmth and compassion. Furthermore, interpersonal acceptance is about being able to forgive when confronted with offenses, arguments, and mistakes. For servant leaders it is important to create an atmosphere of trust where people feel accepted, are free to make mistakes and know that they will not be rejected (Ferch 2005). Hence, it facilitates the development of high-quality interpersonal relationships through a better understanding of the behavior of others. Servant leaders are not revengeful or eager to get even, this creates a setting that brings out the best in people.

(8) Stewardship: the willingness to take responsibility for the larger institution and go for service instead of control and self-interest (Block 1993). Leaders should not only act as caretakers, but also act as role models (Hernandez 2008). By setting the right example, leaders can stimulate others to act in the common interest. Stewardship is closely related to social responsibility, loyalty, and team work. These constructs all "represent a feeling of identification with and sense of obligation to a common good that includes the self but that stretches beyond one's own self-interest" (Peterson and Seligman 2004, p. 370).

In conclusion, based on an analysis of the servant leadership literature and interviews with servant leaders, these eight aspects were selected as the best indicators of servant leadership and were therefore included in the empirical design.

\section{Study 1}

\section{Method}

Participants The composite sample of this study consisted of four samples, including 668 persons from the Netherlands. Sample 1 was collected through an open online survey. Participants received an e-mail sent to the mailing list of the Greenleaf Center for Servant Leadership Europe. Additionally, an invitation was put on the website of the Center and e-mails were sent to people belonging to the social networks of the authors. All recipients were asked to forward the invitation to people they knew. The webpage with the start page of the questionnaire was checked by 504 people of whom 213 persons filled out the complete list. Sample 2 was also an open online survey conducted within the network of a Master student. Five hundred and three people checked out the webpage of whom 202 people filled out the complete list. The participants were employed in diverse occupations (e.g., finance, consultancy, health care, education, civil service). Sample 
3 was obtained from a study at a high school. The teaching staff (678 persons) was asked in a personal e-mail to participate in a survey on leadership and well-being. One hundred and sixty teachers completed the survey. Sample 4 was a combined sample of small studies conducted in a clinic, a restaurant, several shops, a fire brigade, and a small factory and included 93 people. All respondents in these samples participated voluntary.

The mean age of this composite sample was 40.6 years $(\mathrm{SD}=12.1)$, with 11.2 years $(\mathrm{SD}=10.4)$ of work experience. The sample consisted of $47.9 \%$ men and $52.1 \%$ women. Forty-two percent worked in a profit organization, $58 \%$ in a non-profit organization. The majority had a male supervisor $(71.5 \%)$ versus $28.5 \%$ with female supervisor.

Measures Based on our conceptual model, we operationalised the eight earlier mentioned aspects. After the content analysis for critical aspects of servant leadership, we checked the operationalisations of related constructs to develop a first pool of items. Most items were specifically formulated for our measure, except those for empowerment that were taken from the Konczak et al. (2000) measure. All items were positively formulated, except for three items that were aimed at the forgiveness aspect of interpersonal acceptance.

These items were subjected to a critical review by three master students who had extensively studied the literature on servant leadership as part of their thesis project. They had to decide to what extent they felt that items reflected servant leadership - as described in the eight concepts above-and whether crucial aspects had been overlooked. Based on their opinions, from the original item pool of 110 items, 20 items were removed, and 9 new items were added, reaching a total of 99 items. All people in Study 1 responded to these 99 SLS items that were formulated in this item generation phase.

\section{Results}

In order to achieve a psychometrically sound multi-dimensional measure that holds under cross-validation, exploratory factor analysis was used as a first step. The primary goal of exploratory factor analysis is to reduce a large set of measured variables to a smaller set. The goal was to reduce the set of 99 items so that only the items remained that best exemplified one of the proposed dimensions without loading too high on one or more of the other dimensions. Exploratory factor analysis can be used to determine whether the hypothesized dimensions actually are reflected in the collected data. It should, however, be noted that even with exploratory factor analysis, theory remains an important guideline to decide which items to keep and which items to remove (Henson and Roberts 2006).
The first stage in analyzing the data with exploratory factor analysis is checking the conditions for a stable factor structure (Ferguson and Cox 1993). This requires that the sample size is large enough. The two most frequently used criteria are the absolute minimum number of subjects and the relative number indicated by the subjects-to-variables ratio. Somewhere between 100 and 300 subjects have been suggested as the minimum number of subjects, whereby Guadagnoli and Velicer (1988) even suggested that 100 subjects may be acceptable. With 668 subjects in our composite sample, this criterion is absolutely met. Recommendations for the subject-to-variable ratio range between 2:1 and 10:1. The generally accepted minimum for reaching a stable factor structure is 5:1 (Ferguson and Cox 1993). In our sample this ratio was $6.7: 1$, thus higher than the generally accepted minimum ratio.

The next step is to check whether the items are multivariate normally distributed by checking their skewness and kurtosis. Following Ferguson and Cox (1993), we checked whether no more than $25 \%$ exceeded the range of \pm 2.0 . With respect to skewness, no items fell outside this range. With respect to kurtosis, only 6 out of $99(6 \%)$ fell outside the range.

We then applied the Kaiser-Meyer-Olkin test and the Bartlett's test of sphericity to make sure that the correlation matrix was appropriate to produce a factor structure not found by chance. The Kaiser-Meyer-Olkin test was .980 , well above the required minimum value of .5 . The approximate chi-square of the Bartlett's test of sphericity was significant $(51094.251$, df $=4851, p<.001$ ), indicating that a discoverable factor structure exists in the data. Therefore, we can conclude that the necessary conditions for finding a stable factor structure exist within the dataset.

In stage 2 the number of factors to be extracted from the data is determined. The three most used techniques are the Kaiser 1 rule that is extracting the number of factors with an Eigenvalue higher than 1, the Scree test, and parallel analysis (Hayton et al. 2004). The Kaiser 1 rule has the tendency to overestimate the number of factors; the Scree test is vulnerable to subjective interpretation on where the break in the plot is. Parallel analysis is considered the most accurate method to determine the number of factors to retain. We used both the Kaiser 1 rule to determine the maximum number of factors and parallel analysis for the exact number, following the guidelines and syntax provided by Hayton et al. (2004).

Fourteen factors were found with an Eigenvalue higher than 1. The Eigenvalues were 41.934, 4.927, 2.820, 2.251, $1.892,1.800,1.566,1.418,1.411,1.310,1.180,1.115$, 1.073 , and 1.010. With parallel analysis a random generated set of Eigenvalues is compared to the empirically derived Eigenvalues. Using the syntax provided by Hayton et al. (2004) 50 random datasets were generated with SPSS 
each consisting of 668 persons and 99 variables. Next, all datasets were subjected to a factor analysis. The Eigenvalues of the first 14 factors were averaged across these 50 datasets. To determine the number of factors in our dataset, both plots were compared. The number of extractable factors is indicated by the point immediately before the point where both lines cross. The averaged random Eigenvalues were 1.857, 1.810, 1.773, 1.737, 1.706, 1.678, $1.625,1.599,1.577,1.552,1.533,1.508$, and 1.490. A comparison of both lists indicates that the crossing point lies between factor 6 and 7. Therefore, we may conclude that six factors probably is the most accurate number to be extracted from the data.

In stage 3 the items that best fitted the six factors mentioned above were selected. Varimax rotation was used since this method seeks to maximize the variance across all factors. Items had to have a minimum factor loading of 4 on one-factor only, and the minimum difference in factor loading on the remaining five factors of .2 (Ferguson and Cox 1993). Subsequent factor analyses were performed, starting with all 99 items. Each time the items with the highest cross-loadings were excluded. Finally 28 items remained, whereby the six factors explained $65 \%$ of the variance. Based on item content, we labeled six dimensions, namely empowerment, accountability, standing back, authenticity, courage, and forgiveness. It should be noted that a comparison of the original varimax rotated component matrix with the oblimin pattern matrix showed that both matrices were comparable, lending support to this 28-item selection.

Due to the results of the factor analysis we had to review the measurement of the eight anticipated constructs. For the interpersonal acceptance dimension, only the items explicitly focusing on forgiveness stayed as a separate factor; therefore we decided to rename this dimension forgiveness. The empathy items loaded on several other dimensions and were removed. In comparing the six dimensions with our original conceptual model, it is striking that the items for humility had disappeared. So, if we would purely follow the psychometric criteria, we would lose a very important conceptual element of servant leadership. Double checking the factor structure showed that most of these items had double loadings on the dimensions Standing back and empowerment, often as high as .50 on both factors. In a sense, humility was a seventh factor loading between these dimensions. It is interesting that from a theoretical perspective this makes perfect sense since servant leaders combine a service attitude with empowerment, and are most successful when they are humble. Therefore, we decided to keep the six items that exemplified the Humility dimension best.

Finally, we found that the items for the eighth dimension-stewardship_-did not accurately reflect this construct. Nevertheless, we hold the view that it is an important aspect in the whole concept of servant leadership. Therefore, we decided to keep it as a dimension, but we reformulated two items and added three new ones. The SLS now counted 39 items representing eight hypothesized dimensions. These 39 SLS items were subjected to a confirmatory factor analysis in a new sample in Study 2.

Study 2

\section{Method}

Participants The sample of this study was collected through an open online survey. Participants were invited in an online newsletter which was sent to civil servants throughout the Netherlands asking for volunteers to participate in a study on leadership. No incentive was offered for participation. The webpage was checked by 734 people of whom 263 persons filled out the survey.

The mean age of this fifth sample was 47.3 years $(\mathrm{SD}=9.1)$, with 3.7 years $(\mathrm{SD}=4.7)$ of work experience at their present job. The sample consisted of $64.2 \%$ men and $35.8 \%$ women. The majority had a male supervisor $(80.5 \%)$ versus $19.5 \%$ with a female supervisor.

Measures Servant leadership. Servant leadership was measured with 39 items derived from the exploratory factor analysis in Study 1.

\section{Results}

In Study 1 we reduced the number of items with exploratory factor analysis to keep those with the strongest indications of conforming to the proposed underlying structure. In Study 2 we used confirmatory factor analysis so that the hypothesized factor structure can be tested for its fit to the observed covariance structure (Henson and Roberts 2006). It is the preferred analysis method if theory underlies the measured constructs. With confirmatory factor analysis different models can be tested and compared. In addition, information is provided (i.e., modification indices) to guide us towards further refining our measure.

We tested the stability of the eight-factor model with the 39 items derived in the first step. MPlus 5.1 (Muthén and Muthén 2007) was used to carry out all the confirmatory factor analyses. First, a one-factor model where all items loaded on one servant leadership factor was tested. The chisquare was 2934.7, $\mathrm{df}=702, \quad p<.001, \quad \mathrm{CFI}=.65$, $\mathrm{TLI}=.63, \mathrm{SRMR}=.09, \mathrm{AIC}=27966.4, \mathrm{RMSEA}=.11$. Next, the eight-factor model derived from the analysis of Study 1 was tested. The eight servant leadership factors were allowed to correlate. The chi-square was 1488.7, $\mathrm{df}=674, p<.001, \mathrm{CFI}=.87, \mathrm{TLI}=.86, \mathrm{SRMR}=.06$, 
$\mathrm{AIC}=26576.3, \mathrm{RMSEA}=.07 . \mathrm{A}$ comparison of these results confirms that the survey is multi-dimensional. The relative fit indices of this eight-factor model are already reasonable and the chi-square of the eight-factor model is significantly better than that of the one-factor model $\left(\Delta \chi^{2}=1466.0, \mathrm{df}=21, p<.001\right)$.

Because the relative fit indices of the eight-factor model-with values lower than .90 for CFI and TLIindicate some kind of model misfit, we checked the loadings on the factors. It turned out that all items loaded significantly on their respective factors with standardized factor loadings between .46 and .86 . It is likely that the misfit is due to overlap between factors. Therefore, the modification indices were checked for possible misspecification in the model. We eliminated those items that according to the modification indices had high double loadings in this study. Three items from the empowerment scale, two stewardship items, one standing back item, one courage item, one humility item, and one item from the authenticity scale-were consequently removed. This increased the fit of this model to a chi-square of 623.5, $\mathrm{df}=377, \mathrm{CFI}=.93, \mathrm{TLI}=.92, \mathrm{SRMR}=.05, \mathrm{AIC}=$ 19354.6, RMSEA $=.05$. The standardized solution of this eight-factor model is shown in Table 1.

Our survey now consisted of eight factors captured by 30 items which could empirically be differentiated and conceptually interpreted. Now, we had to test it in another study. In Study 1, the humility items cross-loaded on empowerment and on standing back. By eliminating the items with cross-loadings it is expected that this issue is resolved as well. To check whether this is correct, we compared in Study 3 the fit of four models: the eight-factor model, a six-factor model with all empowerment, humility and standing back items loading on one-factor and twoseven-factor models with the humility items also loading on the empowerment dimension or on the standing back factor.

\section{Study 3}

\section{Method}

Participants The composite sample of this study consisted of two samples from the Netherlands, totaling 236 persons. The first sample of Study 3 (sample 6 of this paper) was collected through an open online survey. People at management positions within the network of the researchers were asked to help out with the research by asking their direct reports to fill out the survey anonymously. One hundred and one persons filled out the SLS. The second sample of Study 3 (sample 7 of this paper) was drawn from employees working at gas stations from a large oil company. One hundred and thirty-five people participated. The mean age of this composite sample was 40.1 years $(\mathrm{SD}=10.3)$ with 6.4 years $(\mathrm{SD}=6.2)$ of work experience. The sample consisted of $36.1 \%$ men and $63.9 \%$ women. Within this group the majority had a male supervisor $(79.1 \%$ ) and $20.9 \%$ had a woman as supervisor. As in the previous studies, participation was voluntary.

Measures Servant leadership. Servant leadership was measured with 30 items derived from the results of Study 2.

\section{Results}

The eight-factor model was confirmed in this study, with a chi-square of $562.5, \mathrm{df}=377, \mathrm{CFI}=.94, \mathrm{TLI}=.93$, $\mathrm{SRMR}=.05, \mathrm{AIC}=17150.5, \mathrm{RMSEA}=.05$. The generally accepted values of good fit are close to .95 for the CFI and the TLI, and less than .08 for the SRMR and RMSEA (Fan and Sivo 2007; Hu and Bentler 1998). Next, we compared the fit of this model with the three models that presume that humility is not a separate dimension. The fit of the sixfactor model was significantly lower $\left(\chi^{2}=833.2\right.$, df $=$ $390, \mathrm{CFI}=.87, \mathrm{TLI}=.85, \mathrm{SRMR}=.06, \mathrm{AIC}=17395.1$, $\left.\mathrm{RMSEA}=.07 ; \Delta \chi^{2}=270.7, \mathrm{df}=23, p<.001\right)$. The fit of the seven-factor model with all humility and empowerment items loading on one-factor had a similar low fit $\left(\chi^{2}=800.9, \mathrm{df}=384, \mathrm{CFI}=.87, \mathrm{TLI}=.85, \mathrm{SRMR}=\right.$ $.06, \mathrm{AIC}=17374.8, \mathrm{RMSEA}=.07 ; \Delta \chi^{2}=238.4, \mathrm{df}=7$, $p<.001)$. The fit of the seven-factor model with humility and standing back items one-factor was reasonable, but still significantly less compared to the eight-factor model $\left(\chi^{2}=619.4, \mathrm{df}=384, \mathrm{CFI}=.93, \mathrm{TLI}=.92, \mathrm{SRMR}=\right.$ $.06, \mathrm{AIC}=17193.4, \mathrm{RMSEA}=.05 ; \Delta \chi^{2}=57.2, \mathrm{df}=7$, $p<.001)$. We may, therefore, conclude that we confirmed the factorial validity of the eight-factor model in an independent sample.

To enhance our understanding of the relations between the eight dimensions, we tested the eight-factor model with one underlying second-order factor. With respect to the relative fit indices, the fit of this model approached that of the eight-factor model with all factors interrelated $\left(\chi^{2}=\right.$ 600.1, df $=397$, CFI $=.94, \quad$ TLI $=.93, \quad$ SRMR $=.06$, $\mathrm{AIC}=17148.1$, RMSEA $=.05)$. The standardized factor loadings of the latent factors on this second-order servant leadership factor were .92 for empowerment, .40 for accountability, .84 for standing back, .82 for humility, .71 for authenticity, .53 for courage, .19 for forgiveness, and .92 for stewardship. Seven out of eight factors loaded moderately to high on this second-order factor.

The reliability in terms of internal consistency was good for all scales. The combined sample of all three studies showed Cronbach's alpha's of .89 for empowerment (7 items), .81 for accountability (3 items), .76 for standing back ( 3 items), .91 for humility ( 5 items), .82 for authenticity 
Table 1 Factor loadings confirmatory factor analysis, Study $2(N=263)$, standardized values

\begin{tabular}{llllllll}
1 & 2 & 3 & 4 & 5 & 6 & 7 & 8 \\
\hline
\end{tabular}

Empowerment

1. My manager gives me the information I need to do my work well.

2. My manager encourages me to use my talents.

3. My manager helps me to further develop myself.

4. My manager encourages his/her staff to come up with new ideas.

12. My manager gives me the authority to take decisions which make work easier for me.

20. My manager enables me to solve problems myself instead of just telling me what to do.

27. My manager offers me abundant opportunities to learn new skills.

Standing back

5. My manager keeps himself/herself in the background and gives credits to others.

13. My manager is not chasing recognition or rewards for the things he/she does for others.

21. My manager appears to enjoy his/her colleagues' success more than his/her own.

Accountability

6. My manager holds me responsible for the work I carry out.

14. I am held accountable for my performance by my manager.

22. My manager holds me and my colleagues responsible for the way we handle a job.

Forgiveness

7. My manager keeps criticizing people for the mistakes they have made in their work (r).

15. My manager maintains a hard attitude towards people who have offended him/her at work (r).

23. My manager finds it difficult to forget things that went wrong in the past (r).

16. My manager takes risks and does what needs to be done in his/her view.

Authenticity

9. My manager is open about his/her limitations and weaknesses.

17. My manager is often touched by the things he/she sees happening around him/her.

24. My manager is prepared to express his/her feelings even if this might have undesirable consequences.

28. My manager shows his/her true feelings to his/her staff.

Humility

10. My manager learns from criticism.

18. My manager tries to learn from the criticism he/she gets from his/her superior.

25. My manager admits his/her mistakes to his/her superior.

29. My manager learns from the different views and opinions of others.

30. If people express criticism, my manager tries to learn from it.

Stewardship

11. My manager emphasizes the importance of focusing on the good of the whole.

19. My manager has a long-term vision.

26. My manager emphasizes the societal responsibility of our work.

(c) Copyright 2010 by Van Dierendonck and Nuijten. The Servant Leadership Survey may freely be used for scientific purposes. Item numbers in the table refer to the items place in the survey

(4 items), .69 for courage (2 items), .72 for forgiveness (3 items), and .74 for stewardship (3 items).

In conclusion, at this stage of the development of the instrument, our survey consisted of eight factors captured by 30 items which could empirically be differentiated and conceptually interpreted. The following step was to use this instrument in a new study in the United Kingdom. This fourth study was added as a first test for the cross-cultural validity of our measure. The data of studies 1,2 , and 3 were collected within the Netherlands. Although Table 1 shows the English language version, the original questionnaire is in Dutch. Both translation and implicit leadership models could have influenced the factorial structure. According to the Globe study (House et al. 2004), the Netherlands and the United Kingdom are positioned in different clusters, that is the Germanic and Anglo clusters. 
As such, information on the cross-cultural stability of the underlying factorial model through a replication of the eight-factor structure is essential to build a greater trust in the stability of the instrument.

\section{Study 4}

\section{Method}

Participants The study was conducted online as a leadership study. Respondents were recruited via a panel firm located in the United Kingdom. Three hundred and eightyfour people participated. The mean age of this sample was 42.5 years $(\mathrm{SD}=9.9)$ with 6.4 years $(\mathrm{SD}=5.5)$ of work experience. The sample consisted of $37.2 \%$ men and $62.8 \%$ women.

Measures Servant leadership. Servant leadership was measured with 30 items derived from the results of Study 2 . The translation into English was first done by both authors separately. Following, both versions were compared and differences reconciled by a back-translation procedure. This version was cross-checked by a professional translator with an English language degree.

\section{Results}

The eight-factor model was confirmed in this study, with a chisquare of $1197.7, \mathrm{df}=377, \mathrm{CFI}=.93, \mathrm{TLI}=.92, \mathrm{SRMR}=$ .07, AIC $=29733.1$, RMSEA $=.05$. The goodness-of-fit indices for the English version are similar to the one's reported for the Dutch version in Study 2 and 3. We can, therefore, conclude that we found confirmation for the cross-cultural factorial validity of the eight-factor model in an UK sample.

Similar to Study 3, we again tested the eight-factor model with one underlying second-order factor. With respect to the relative fit indices, the fit of this model fit was slightly less compared to the eight-factor model with all factors interrelated $\left(\chi^{2}=1314.4, \mathrm{df}=397, \mathrm{CFI}=.92, \mathrm{TLI}=.91\right.$, $\mathrm{SRMR}=.06, \mathrm{AIC}=29809.9$, RMSEA $=.08$ ). The standardized factor loadings of the latent factors on this secondorder servant leadership factor were .90 for empowerment, .17 for accountability, .90 for standing back, .93 for humility, .82 for authenticity, .58 for courage, .60 for forgiveness, and .93 for stewardship. Again, seven out of eight dimensions loaded moderately to high on this second-order. However, in this UK sample it was accountability that loaded lower than the others. Despite the relative low factor loading within this specific sample, it may be good to realize that accountability has been positioned as an essential element of the 'leader' aspect of servant leadership and is therefore kept within the instrument.
The reliability in terms of internal consistency was good for all scales. Cronbach's alpha's were .94 for empowerment ( 7 items), .93 for accountability ( 3 items), .92 for standing back ( 3 items), .95 for humility ( 5 items), .76 for authenticity (4 items), .91 for courage ( 2 items), .90 for forgiveness ( 3 items), and .87 for stewardship ( 3 items).

In summary, we have found support for the eight-factor structure from the exploratory phase in two new samples in the Netherlands and in the UK. The results of the secondorder model of both samples show that the strongest indicators of servant leadership seem to be empowerment, standing back, humility, and stewardship with factor loadings of .80 and higher. Forgiveness and accountability deviate most from the other six factors. For forgiveness this could be explained in that it only applies in situations where something has gone wrong as opposed to the other factors that focus on more generally applicable behaviors. Accountability is the factor that strongest exemplifies the leader part of servant leadership.

\section{Phase 2: Content Validity of the SLS}

To study the content validity of the SLS it is compared to two other measures of servant leadership, a one-dimensional measure (Ehrhart 2004) and a multi-dimensional measure (Liden et al. 2008). Given that all three measures focus on servant leadership, considerable overlap is to be expected, indicating convergent validity. However, we expect some discriminant validity as well, because the SLS covers essential aspects of servant leadership that other scales have neglected.

Servant leadership has many parallels with transformational leadership, but moves beyond transformational leadership with its alignment of leaders' and followers' motives (Barbuto and Wheeler 2006). More particularly, a servant leader is genuinely concerned with serving followers (Greenleaf 1977), while transformational leaders have a greater concern for the strategic use of followers to reach organizational goals (Stone et al. 2004). With a leader whose main focus is on the people within the organization, there is room for safe and secure relationships. Furthermore, we expect that servant leadership will distinguish itself from transformational leadership by several essential characteristics emphasizing the focus on the followers.

Servant leadership can also be related to the more recent work on ethical leadership (Brown et al. 2005). Ethical leadership is a more normative approach that focuses on the question of appropriate behavior in organizations. Ethical leadership and servant leadership share characteristics such as care for people, integrity, trustworthiness, and serving the good of the whole. In ethical leadership, 
however, the emphasis is more on directive and normative behavior, whereas servant leadership has a stronger focus on the developmental aspect of the followers. It is not so much focused on the norms within an organization, but more on how individuals themselves want and can do things. Considering the importance of caring for people and being trustworthy in both types of leadership, we expect to find high correlations between servant leadership and ethical leadership.

Another theory of leadership is the leader-member exchange (LMX) theory (Dansereau et al. 1975); it describes the relation between and follower as an exchange relationship. Leaders use their position power to develop exchange relationships with different followers. It assumes that leaders pay attention to the specific needs of individual followers and approach each member of their work group individually. More particularly, LMX theory emphasizes how leaders work with their followers on a one-to-one basis to develop high-quality relationships with each of them (Graen and Uhl-Bien 1995). Within this relationship, respect for each other's capabilities, reciprocal trust and the expectation of partnership are essential. Therefore, it is expected that followers of servant leaders will experience a high LMX quality in this relationship.

We also compare servant leaders to charismatic leaders, who are similar to servant leaders in that they have clear goals for their followers, communicate high expectations for followers, exhibit confidence in followers' abilities to meet these expectations (Shamir et al. 1993; Shamir and Howell 1999), and are courageous (Murphy and Ensher 2008). However, other characteristics of charismatic leaders also include dominant and manipulative behavior, showing no regard for the benefits of others (Northouse 2007). In this respect they are very different from servant leaders, which we expect to find in the data.

The final leadership style to which we will compare servant leadership is transactional leadership. Transactional leaders do not individualize the needs of followers or focus on their personal development. Moreover, they exchange things of value with subordinates to advance their own and their followers' agenda (Howell and Avolio 1993). Transactional leadership is most likely found in well-ordered societies (Bass et al. 2003), and probably most effective when quantitative performance is required (Hoyt and Blascovich 2003). Exhibiting transactional leadership means that followers agree with, accept, or comply with the leader in exchange for praise, rewards, and resources or the avoidance of disciplinary action. Transactional leadership, in its corrective form is called active management by exception. It means that the leader sets standards for compliance and performance, and may punish followers for not meeting these standards (Bass et al. 2003). As such, this leadership style implies less attention for nurturing and facilitating. Research has shown that trust, satisfaction and work group cohesion are greater for transformational leaders than for transactional leaders (Hoyt and Blascovich 2003). We therefore expect punishment behavior to be only weakly related to servant leadership behavior.

\section{Method}

\section{Participants}

For this phase a composite sample was used by combining the eight samples used in the four studies of Phase 1. This composite sample consisted of 1571 persons, 1187 filled out the Dutch version and 384 filled out the English version. Different concepts were measured in each of the samples, all on a six-point Likert scale, except for the scale by Liden et al. (2008) that used a seven-point Likert scale.

\section{Measures}

SLS. The 30-item version derived from the development phase was used.

Servant leadership, a one-dimensional scale. A general measure of servant leadership developed by Ehrhart (2004) was included in sample 3, Study 1 . This measure consists of 14 items focused on ethical behaviors and prioritization of subordinates' concerns. It is used as a one-dimensional general scale of servant leadership. The internal consistency is .95 .

Servant leadership scale. This 28 -item scale of servant leadership developed by Liden et al. (2008) was used in Study 4 (UK sample). The scale consists of seven dimensions: emotional healing, creating value of the community, conceptual skills, empowering, helping subordinates grow and succeed, putting subordinates first, and behaving ethically. The internal consistencies are $.90, .92, .86, .91, .94$, .89 , and .90 , respectively.

Transformational leadership. Transformational leadership was measured with the scale developed by Rafferty and Griffin (2004) in both samples in Study 3, samples 6 and 7. This scale consists of five 3-item subscales: vision, inspirational communication, intellectual stimulation, supportive leadership, and personal recognition. The internal consistencies are acceptable: .64, .63, .74, .77, and .85, respectively.

Ethical leadership. Ethical leadership was measured with the 10-item scale developed by Brown et al. (2005) in samples 3 and 4 in Study 1. The internal consistency is high (alpha $=.95)$.

$L M X-7$. Leader-member exchange was measured with Scandura and Graen's (1984) seven-item measure of LMX. This scale was included in sample 1 . The internal consistency is .92 . 
Charismatic leadership. Perceived charisma of the leader was measured with a six-item scale developed by Damen et al. (2008) based on the work of Bass (1985), and Conger and Kanungo (1987). The scale was included in sample 3, Study 1. The internal consistency of this scale is 94.

Punishment behavior. Contingent punishment has been suggested as an element of transactional leadership by Podsakov et al. (1984). It was measured with their threeitem measure in sample 7 , Study 3 . The internal consistency was .75 .

Results

For the combined Dutch samples, Table 2 shows the correlations between the eight servant leadership factors and 10 other leadership (sub)scales. The intercorrelations between the eight servant leadership dimensions are in line with the differences between the dimensions, correlations ranging from .02 to .71. Support for the content validity can be found in the correlation pattern of Ehrhart's one-dimensional servant leadership scale and ethical leadership with empowerment, standing back, humility, authenticity, and stewardship. Given the conceptual overlap, high correlations were expected and found, whereas the correlations with punishment behavior turned out to be moderate to low as we predicted. This is where servant leadership behavior clearly differs from transactional leadership. The patterns of transformational leadership, LMX-7 and charismatic leadership with the eight servant leadership dimensions of the SLS are similar in that they reveal strong correlations with empowerment, humility, and stewardship, followed by similarly strong relations with authenticity and standing back. The lowest correlations were generally found with accountability, courage, and forgiveness, confirming their unique character.

For the UK sample, Table 3 shows the correlations between the eight servant leadership factors of our measure and the seven of the Liden et al. (2008) measure. The intercorrelations between the eight servant leadership dimensions are in line with the differences between the dimensions, with correlations ranging from .08 to .81. Support for the content validity can be found in the correlation pattern between both measures, ranging between .02 and .85. Given the conceptual overlap, high correlations were expected and found. Of the eight SLS dimensions, empowerment, standing back, humility, and stewardship showed the strongest overall overlap with the Liden et al. scale. The lowest correlations were found for accountability.

Table 2 Descriptives and intercorrelations among leadership dimensions (Dutch composite sample, $N=1167$ )

\begin{tabular}{|c|c|c|c|c|c|c|c|c|c|c|c|c|c|c|c|c|c|c|c|c|}
\hline & $M$ & SD & $N$ & 1 & 2 & 3 & 4 & 5 & 6 & 7 & 8 & 9 & 10 & 11 & 12 & 13 & 14 & 15 & 16 & 17 \\
\hline \multicolumn{21}{|l|}{ Servant Leadership Survey } \\
\hline 1. Empowerment & 4.39 & .90 & 1187 & & & & & & & & & & & & & & & & & \\
\hline 2. Accountability & 4.86 & .70 & 1187 & .46 & & & & & & & & & & & & & & & & \\
\hline 3. Standing back & 3.67 & .95 & 1187 & .54 & .15 & & & & & & & & & & & & & & & \\
\hline 4. Humility & 4.13 & .93 & 1187 & .71 & .30 & 60 & & & & & & & & & & & & & & \\
\hline 5. Authenticity & 3.62 & .94 & 1187 & .55 & .17 & .52 & .63 & & & & & & & & & & & & & \\
\hline 6. Courage & 3.86 & 1.08 & 1187 & .47 & .24 & .29 & .39 & .35 & & & & & & & & & & & & \\
\hline 7. Forgiveness & 3.87 & 1.05 & 1187 & .14 & .02 & .15 & .22 & .08 & $-.02^{+}$ & & & & & & & & & & & \\
\hline 8. Stewardship & 4.43 & .91 & 495 & .71 & .40 & .52 & .64 & .48 & .49 & $.03^{+}$ & & & & & & & & & & \\
\hline \multicolumn{21}{|l|}{ Transformational leadership } \\
\hline 9. Vision & 4.60 & .80 & 235 & .63 & .38 & .40 & .46 & .32 & .27 & $-.03^{+}$ & .60 & & & & & & & & & \\
\hline 10. Inspirational communication & 4.58 & .70 & 235 & .76 & .36 & .58 & .65 & .43 & .37 & $-.06^{+}$ & .63 & .61 & & & & & & & & \\
\hline 11. Intellectual stimulation & 4.11 & .80 & 235 & .65 & .36 & .33 & .45 & .44 & .41 & -.19 & .54 & .49 & .56 & & & & & & & \\
\hline 12. Supportive leadership & 4.37 & .81 & 235 & .77 & .25 & .64 & .73 & .55 & .27 & -.14 & .55 & .55 & .69 & .58 & & & & & & \\
\hline 13. Personal recognition & 4.51 & .89 & 235 & .74 & .28 & .52 & .60 & .47 & .29 & $-.09^{+}$ & .53 & .51 & .68 & .60 & .69 & & & & & \\
\hline \multicolumn{21}{|l|}{ Other leadership dimensions } \\
\hline 14. Punishment behavior & 4.36 & .76 & 135 & .22 & .41 & $.12^{+}$ & .29 & $.14^{+}$ & .23 & -.41 & .31 & .15 & .31 & .40 & .20 & .26 & & & & \\
\hline 15. Ethical leadership & 4.36 & .86 & 253 & .74 & .39 & .64 & .81 & .61 & .50 & .34 & .76 & - & - & - & - & - & - & & & \\
\hline 16. Charismatic leadership & 3.84 & 1.16 & 180 & .81 & .60 & .65 & .74 & .62 & .57 & .32 & - & - & - & - & - & - & - & - & & \\
\hline 17. LMX-7 & 3.39 & .83 & 209 & .85 & .32 & .61 & .76 & .70 & .42 & .52 & - & - & - & - & - & - & - & - & - & \\
\hline 18. Servant leadership (Ehrhart) & 3.73 & .99 & 180 & .84 & .64 & .71 & .85 & .73 & .58 & .31 & - & - & - & - & - & - & - & - & .85 & - \\
\hline
\end{tabular}

Note: All correlations significant $p<.05$, except ${ }^{+} p=$ n.s 
Table 3 Descriptives and intercorrelations among leadership dimensions (Study 4, UK sample, $N=384$ )

\begin{tabular}{|c|c|c|c|c|c|c|c|c|c|c|c|c|c|c|c|c|}
\hline & $M$ & SD & 1 & 2 & 3 & 4 & 5 & 6 & 7 & 8 & 9 & 10 & 11 & 12 & 13 & 14 \\
\hline \multicolumn{17}{|l|}{ Servant Leadership Survey } \\
\hline 1. Empowerment & 4.06 & 1.12 & & & & & & & & & & & & & & \\
\hline 2. Accountability & 4.84 & .81 & .22 & & & & & & & & & & & & & \\
\hline 3. Standing back & 3.61 & 1.27 & .81 & .13 & & & & & & & & & & & & \\
\hline 4. Humility & 3.56 & 1.12 & .77 & .11 & .77 & & & & & & & & & & & \\
\hline 5. Authenticity & 3.50 & 1.23 & .55 & .12 & .57 & .61 & & & & & & & & & & \\
\hline 6. Courage & 3.61 & 1.23 & .51 & $.08^{+}$ & .43 & .46 & .39 & & & & & & & & & \\
\hline 7. Forgiveness & 2.81 & 1.33 & .52 & .11 & .51 & .58 & .27 & .25 & & & & & & & & \\
\hline 8. Stewardship & 3.90 & 1.14 & .76 & .15 & .73 & .80 & .53 & .52 & .52 & & & & & & & \\
\hline \multicolumn{17}{|l|}{ Servant Leadership Scale } \\
\hline 9. Emotional healing & 4.52 & 1.52 & .73 & $.09^{+}$ & 67 & .75 & .59 & .45 & .57 & .75 & & & & & & \\
\hline 10. Creating value for community & 3.58 & 1.46 & .60 & $.02^{+}$ & .63 & .64 & .51 & .38 & .38 & .68 & .68 & & & & & \\
\hline 11. Conceptual skills & 4.87 & 1.24 & .72 & .18 & 67 & 69 & .50 & .51 & .47 & .75 & .75 & .62 & & & & \\
\hline 12. Empowering & 4.87 & 1.35 & .74 & .20 & .60 & .80 & .45 & .45 & .47 & .62 & .69 & .53 & .64 & & & \\
\hline 13. Helping subordinates grow and succeed & 4.16 & 1.51 & .85 & .14 & .76 & .79 & .57 & .49 & .51 & .77 & .79 & .72 & .75 & .73 & & \\
\hline 14. Putting subordinates first & 3.74 & 1.39 & .75 & $.04^{+}$ & .76 & .77 & .57 & .49 & .48 & .75 & .76 & .77 & .72 & .66 & .85 & \\
\hline 15. Behaving ethically & 4.28 & 1.46 & .71 & .10 & .76 & .77 & .57 & .41 & .54 & .75 & .77 & .77 & .75 & 62 & .77 & .80 \\
\hline
\end{tabular}

Note: All correlations significant $p<.05$, except ${ }^{+} p=$ n.s

To enhance our insight in the connections underlying the 18 leadership scales in the Dutch composite sample, an exploratory factor analysis was performed with MPlus 5.1. Since different scales were used in the different samples, missing values analysis was used to examine the overall underlying pattern (Muthén and Muthén 2007). With maximum likelihood estimation, MPlus uses missing values analysis to calculate an overall covariance table that is used as input for the factor analysis. The program provides goodness-of-fit indices to determine the most likely number of factors underlying the 18 scales. For the one-factor model, the chi-square was $609.9, \mathrm{df}=135, \mathrm{CFI}=.92$, $\mathrm{TLI}=.92, \mathrm{SRMR}=.08, \mathrm{AIC}=23861.8, \mathrm{RMSEA}=.06$. For the two-factor model the chi-square was 278.0, $\mathrm{df}=$ $118, \quad \mathrm{CFI}=.97, \quad \mathrm{TLI}=.97, \quad \mathrm{SRMR}=.06, \quad \mathrm{AIC}=$ 23563.9, RMSEA $=.04$. For the three-factor model it was $186.0, \mathrm{df}=102, \mathrm{CFI}=.99, \mathrm{TLI}=.98, \mathrm{SRMR}=.05$, $\mathrm{AIC}=23503.9$, RMSEA $=.04$. Finally, for the four-factor model the chi-square was $114.8, \mathrm{df}=87, \mathrm{CFI}=1.00$, $\mathrm{TLI}=.99, \mathrm{SRMR}=.04, \mathrm{AIC}=23462.6, \mathrm{RMSEA}=.03$. Although there is significant evidence for a four-factor model, the factor structure of that model showed that on one-factor, only one leadership scale loaded higher than 40 . Therefore, Table 4 shows the oblique geomin rotated loadings provided by MPlus for the three-factor model.

Given the high loading of empowerment, accountability, vision, and intellectual stimulation, factor one can be interpreted as the 'leader'-side of servant leadership. The
Table 4 Factor structure second-order exploratory factor analysis (oblique geomin rotation, Dutch composite sample, $N=1167$ )

\begin{tabular}{|c|c|c|c|}
\hline & I & II & III \\
\hline \multicolumn{4}{|l|}{ Servant Leadership Survey (SLS) } \\
\hline 1. Empowerment & .75 & & \\
\hline 2. Accountability & .81 & -.34 & \\
\hline 3. Standing back & & .73 & \\
\hline 4. Humility & & .66 & \\
\hline 5. Authenticity & & .76 & \\
\hline 6. Courage & .42 & & \\
\hline 7. Forgiveness & & & .88 \\
\hline 8. Stewardship & .67 & & \\
\hline \multicolumn{4}{|l|}{ Transformational leadership } \\
\hline 9. Vision & .84 & & \\
\hline 10. Inspirational communication & .70 & & \\
\hline 11. Intellectual stimulation & .77 & & \\
\hline 12. Supportive leadership & .35 & .62 & \\
\hline 13. Personal recognition & .57 & .32 & \\
\hline \multicolumn{4}{|l|}{ Other leadership dimensions } \\
\hline 14. Punishment behavior & .44 & & -.56 \\
\hline 15. Ethical leadership & .40 & .55 & \\
\hline 16. Charismatic leadership & .60 & .32 & \\
\hline 17. LMX-7 & .68 & .32 & \\
\hline 18. Servant leadership (Ehrhart) & .38 & .66 & \\
\hline
\end{tabular}

Notes: Factor loadings $>.30$ are depicted. Factor loading are significant $p>.05$ 
'leader'-side involves enabling followers to express their talents by setting clear goals, providing a meaningful work environment, challenges and the necessary tools and conditions.

Factor two represents the 'servant'-side of servant leadership, it is the 'service attitude' factor. The scales standing back, humility, authenticity, supportive leadership, and ethical leadership signify the willingness to support, to listen to and to serve others. It is about being able to be authentic and stand back, thereby allowing the employees to flourish.

Factor three, the forgiveness factor indicates that errors are part of the job, that mistakes can enhance learning, and that grudges are dysfunctional. It is about forgiving people instead of punishing them, looking forward instead of looking back. Forgiveness and contingent reward load high on this third factor.

The UK sample had no missing values and was analyzed with SPSS. The second-order exploratory factor analysis suggested two factors with an Eigenvalue larger than 1 (9.380 and 1.128) that were also easy to interpret (see Table 5); factor one being the servant leadership and factor two the accountability factor. The UK data suggests that the big difference between both measures of servant leadership is that our measure includes accountability and forgiveness.

Table 5 Factor structure second-order exploratory factor analysis, UK Sample $(N=384)$

\begin{tabular}{lll}
\hline & I & II \\
\hline Servant Leadership Survey (SLS) & & \\
1. Empowerment & .88 & .92 \\
2. Accountability & & \\
3. Standing back & .86 & \\
4. Humility & .89 & \\
5. Authenticity & .67 & \\
6. Courage & .57 & -.41 \\
7. Forgiveness & .62 & \\
8. Stewardship & .88 & \\
Servant leadership (Liden et al.) & & \\
9. Emotional healing & .88 & \\
10. Creating value for community & .79 & \\
11. Conceptual skills & .84 & \\
12. Empowering & .78 & \\
13. Helping subordinates grow and succeed & .92 & \\
14. Putting subordinates first & .90 & \\
15. Behaving ethically & .88
\end{tabular}

Notes: Factor loadings $>.30$ are depicted (oblique rotation). Factor loading are significant $p>.05$
Given the correlation tables and the results from the second-order factor analyses, we may safely conclude we have found support for the construct validity of the SLS. Although servant leadership has overlap with other leadership styles,-most notably due to its multi-dimensional nature-it also adds unique elements to the leadership field.

\section{Phase 3: Criterion-Related Validity of the SLS}

Given the central role of leaders in the social setting of most organizations, the behavior shown by leaders towards their followers plays an important role as to how supportive a work setting is perceived. Moreover, leadership is an increasingly acknowledged factor for follower well-being (Ilies et al. 2005). There is abundant evidence that a controlling, less supportive leadership style, with vague responsibilities and lack of feedback, is related to lower levels of well-being (Cartwright and Cooper 1994; Sosik and Godshalk 2000; Van Dierendonck et al. 2004). A supportive environment, on the other hand, provides positive affect, a sense of predictability, and recognition of self-worth (Walter and Bruch 2008). As such, it is likely that servant leadership behavior is beneficial for follower engagement, job satisfaction, and performance. To test this hypothesis we used the vitality measure by Ryan and Frederick (1997), Schaufeli et al. (2002) engagement scale, a measure for organizational commitment (Mowday et al. 1979), and two estimates of job satisfaction.

We also wanted to gain insight in the predictive value of our instrument for follower behavior. For this purpose the instrument by Morrison and Phelps (1999) was added to measure extra-role behavior. This included in-role behavior, civic virtue, altruism, and taking charge. Previous studies have shown that supportive leadership is related to organizational citizenship behavior (e.g., Euwema et al. 2007). In addition, we added a measure for self-assessed performance.

Finally, we will discuss the concept of leadership clarity. Leadership clarity, which is the followers consensual perception of clarity of and no conflict over who is the leader (West et al. 2003), is related to favorable performance conditions. The study by West et al. (2003) showed it is related to clear team objectives, commitment to objectives, team member participation, commitment to excellence, and team innovation. One of the objectives behind our measure is to explicitly include the leadership aspect within servant leadership. As such, several of the servant leader factors are expected to be positively related to leadership clarity. 
Method

\section{Participants}

A composite sample of the eight samples in four studies of Phase 1 was used, consisting of 1571 persons. Different concepts were measured in each of the samples.

\section{Measures}

Vitality. Vitality was measured with the seven items of the Subjective Vitality Scale (Ryan and Frederick 1997) and showed an internal consistency of .88. The scale was included in Study 2.

Engagement. Engagement with work was measured with the nine-item short version of the Utrechtse Engagement Scale (Schaufeli et al. 2002). The scales consist of three sub-dimensions: vigor, absorption, and dedication. For a general indication of engagement the average mean score across the nine items was used. The internal consistency is excellent with an alpha of .93 .

Job satisfaction. Job satisfaction was measured in two samples. In sample 2 of Study 1, three items derived from the Michigan Organizational Assessment Questionnaire that focus on global job satisfaction were included (Camman et al. 1979). Internal consistency is .78. In sample 3, five items indicated to which extent employees were satisfied with their leader, management in general, their work environment and their coworkers. Internal consistency is .79. The standardized average score (for each sample separately) was used in the analysis.

Organizational commitment. Organizational commitment was measured in Study 4 with a seven-item scale based on the instrument developed by Mowday et al. (1979). Example items are "I am willing to put in a great deal of effort beyond that normally expected in order to help my organization be successful", and "I am proud to tell others that I am part of the organization I work for". The internal consistency is .94.

Extra-role behavior. Extra-role behavior was measured with the scale of Morrison and Phelps (1999). The scale consists of 23 items divided over four subscales: in-role behavior, civic virtue, altruism, and taking charge. This scale was filled out by the supervisors of 48 of the participants in sample 4 of Study 1 . One leader assessed six persons, five leaders assessed two persons, and 32 leaders assessed one person. The internal consistencies are high, $.91, .72, .87$, and .94 , respectively.

Performance. This is a seven-item scale devised specifically for inclusion in Study 4. Example items are: "I adequately complete assigned duties", and "I perform the tasks that are expected of me". The internal consistency is .84 .

Leadership clarity. This scale is based on the study by West et al. (2003). The scale consists of four items, for example, "it is clear who leads my group/department/ team" and "the leadership position in my group/department/team is debated". It was included in Study 4. The internal consistency is .84 .

\section{Results}

To test the extent that servant leadership is related to jobrelated well-being, the correlations between the eight servant leadership dimensions and well-being at work were calculated, as is shown in Table 6. Engagement and job satisfaction were part of Study 1, so regretfully no correlations with stewardship could be calculated. Nevertheless, the other seven dimensions are positively related to both engagement and job satisfaction. The strongest relations were found for empowerment, accountability, and humility, with correlations ranging between .33 and .62. Stewardship

Table 6 Correlations between servant leadership and subjective outcomes

\begin{tabular}{lccccc}
\hline & Vitality & Engagement & $\begin{array}{l}\text { Job } \\
\text { satisfaction }\end{array}$ & $\begin{array}{l}\text { Organizational } \\
\text { commitment }\end{array}$ & $\begin{array}{l}\text { Performance } \\
\text { (self-assessed) }\end{array}$ \\
\hline 1. Empowerment & $.25^{* *}$ & $.43^{* *}$ & $.62^{*}$ & $.62^{* *}$ & $.21^{* *}$ \\
2. Accountability & $.17^{* *}$ & $.41^{* *}$ & $.33^{*}$ & $.14^{* *}$ & $.32^{* *}$ \\
3. Standing back & $.21^{* *}$ & $.18^{*}$ & $.32^{*}$ & $.54^{* *}$ & $.16^{* *}$ \\
4. Humility & $.23^{* *}$ & $.33^{* *}$ & $.48^{*}$ & $.54^{* *}$ & .09 \\
5. Authenticity & $.20^{* *}$ & $.29^{* *}$ & $.35^{* *}$ & $.36^{* *}$ & .08 \\
6. Courage & .12 & $.23^{* *}$ & $.31^{* *}$ & $.39^{* *}$ & .07 \\
7. Forgiveness & -.04 & .08 & $-20^{* *}$ & $.36^{* *}$ & $.14^{* *}$ \\
8. Stewardship & $.33^{* *}$ & - & $-60^{* *}$ & $.17^{* *}$ \\
\hline
\end{tabular}

Notes: $N=263$ (Study 2) for vitality, $N=202$ (Study 1: sample 2) for engagement, $N=362$ (Study 1: samples 2 and 3) for job satisfaction, and $N=384$ (UK sample, Study 4) for organizational commitment and performance. Stewardship was not included in the studies on job satisfaction and engagement

$* * p<.01, * p<.05$ 
was measured in relation to vitality in Study 2, resulting in a significant positive correlation. In the UK sample, the relations with organizational commitment were even stronger, ranging between .14 and .60. In particular empowerment, standing back, humility, and stewardship are strongly related to commitment. Self-assessed performance was related to five of the eight dimensions, with significant correlations between .14 and .32 (Table 6).

It seems there is clear evidence for the relation between servant leadership and well-being at work. The next question addresses the relation between servant leadership and actual follower behavior. Table 7 shows the correlations of servant leadership and follower extra-role behavior. Given the small sample size (48 employees), the power was low and it was impossible to perform regression or multilevel analyses. Multilevel effects are also not expected given that this sample included 38 leaders, most of them assessing only one person. There appeared to be moderately strong relationships between empowerment and in-role behavior, civic virtue and taking charge. Accountability was related to civic virtue; and humility to civic virtue, altruism, and taking charge. All these correlations confirm the relevance of servant leadership for actual behavior of followers. Interesting is the negative relation of forgiveness with civic virtue. It would seem that illbehaving employees are being excused more often, probably because there is more need to do so (Table 7).

The final question concerns the added value of the SLS to the Liden et al. (2008) servant leadership measure. A multiple regression analysis was performed. To determine the strongest predictors, stepwise was used as entry method. The most important predictors for organizational commitment in addition to variance explained by two dimensions of the Liden et al. measure were empowerment and authenticity. For self-assessed performance, accountability and forgiveness (both part of the SLS) were included in the final equation; none of the Liden et al. measure

Table 7 Correlations between servant leadership and extra-role behavior

\begin{tabular}{lcccc}
\hline & $\begin{array}{l}\text { In-role } \\
\text { behavior }\end{array}$ & $\begin{array}{l}\text { Civic } \\
\text { virtue }\end{array}$ & Altruism & $\begin{array}{c}\text { Taking } \\
\text { charge }\end{array}$ \\
\hline 1. Empowerment & $.30^{*}$ & $.38^{* *}$ & .16 & $.35^{*}$ \\
2. Accountability & .20 & $.28^{*}$ & .19 & .13 \\
3. Standing back & .13 & .18 & -.13 & -.07 \\
4. Humility & .17 & $.35^{*}$ & $.33^{*}$ & $.49^{* * *}$ \\
5. Authenticity & .10 & .08 & .13 & .13 \\
6. Courage & .20 & .03 & .24 & .23 \\
7. Forgiveness & -.08 & $-.29 *$ & -.10 & -.21 \\
\hline
\end{tabular}

Notes: $N=48 \quad$ (Study 1: sample 4) $* p<.05, \quad * * p<.01$, $* * * p<.001$. Stewardship was not included in this sample dimensions were included. Variance in leadership clarity was explained by empowerment, accountability and forgiveness and two dimensions of Liden et al.

So, for all three outcome variables, the SLS showed added value (Table 8). Intriguingly, two beta-coefficients are negative, authenticity in relation to organizational commitment, and "creating value for the community" in relation to leadership clarity. This is most likely caused by the Liden et al. measure, given that the negative beta of authenticity disappeared when only the SLS was included in the regression with organizational commitment and the negative coefficient in relation to leadership clarity remained in the equation with only the Liden et al. measure. A similar effect was already reported in the original article by Liden et al. (2008), where several dimensions showed this phenomenon in relation to extra-role behavior. It suggests the influence of multicollinearity as a result of the strong overlap between the dimensions of the Liden et al. measure.

\section{Discussion}

In this article, we described the development and validation of the SLS. Intrigued by the concept of servant leadership, which encompasses the elements that have been related to effective leadership since the days of Socrates (Williamson 2008), we focused on developing an instrument that establishes, defines and operationalizes the core features of servant leadership. Our focus was on transparent leader behavior that can influence follower well-being and performance. Having completed two qualitative and eight quantitative studies (with almost 1600 participants), we think we have come a long way in getting to the heart of servant leadership. By first defining the dimensions, we increased the chances that the dimensions of the SLS are easy to interpret and can be used in different settings (Venkatraman 1989). After the qualitative research part, the construct validity was determined with exploratory and confirmatory factor analysis. The SLS consists of eight dimensions which have proven stable over several samples in two countries. These eight dimensions cover the most important aspects of servant leadership; furthermore, the survey has added value since it includes essential (servant) leader characteristics that have been neglected in other leadership scales so far. The internal consistency of the subscales turned out to be good across all samples. Finally, evidence for criterion-related validity came from studies relating the eight dimensions to organizational commitment, performance, and leadership clarity.

Considering the above, we may safely conclude that the SLS is a valid and reliable instrument to measure servant leadership. It has one underlying leadership dimension, 
Table 8 Multiple regression analysis, UK sample $(N=384)$

\begin{tabular}{llll}
\hline & $\begin{array}{l}\text { Organizational } \\
\text { commitment }\end{array}$ & $\begin{array}{l}\text { Performance } \\
\text { (self-assessed) }\end{array}$ & $\begin{array}{l}\text { Leadership } \\
\text { clarity }\end{array}$ \\
\hline Servant Leadership Survey (SLS) & & & .15 \\
1. Empowerment & .23 & .12 \\
2. Accountability & & \\
3. Standing back & -.14 & \\
4. Humility & & .18 & \\
5. Authenticity & & \\
6. Courage & & \\
7. Forgiveness & .24 & \\
8. Stewardship & .27 & \\
Servant leadership (Liden et al.) & .17 & \\
9. Emotional healing & & & \\
10. Creating value for community & & \\
11. Conceptual skills & & .13 \\
12. Empowering & .51 & \\
13. Helping subordinates grow and succeed & & \\
14. Putting subordinates first & & \\
15. Behaving ethically & & \\
$R_{\text {aid }}^{2}$ & & \\
\hline
\end{tabular}

Note: Significant beta loadings are depicted

$($ method $=$ stepwise $), p>.05$ 'servant' but also the 'leader' part of servant leadership. Accountability, courage and forgiveness are essential and the most important new additions compared to the existing servant leadership instruments. None of them were included in any of the other servant leadership measures. The secondorder exploratory factor analyses (Tables 4 and 5) suggest that Ehrhart's one-dimensional measure mostly captures the 'service attitude' factor and that the Liden et al. (2008) measure misses out with respect of accountability. Especially empowerment, accountability, and forgiveness appear to be essential factors for effective leadership. These three dimensions provided added explained variance above the Liden et al. (2008) measure in relation to organizational commitment, self-assessed performance, and leadership clarity.

Accountability, as defined in this article, has to our knowledge only been included in the study on empowering leader behaviors by Konczak et al. (2000). However, explicitly giving followers responsibility is an essential element of effective and positive leadership. Accountability not only provides meaning, it is also beneficial for selfdetermination (feeling competent and autonomous), and therefore, provides a means to gain self-respect. Courage means the willingness to stand up and fight for what you believe, despite potential criticism and adversity. Servant leaders are pioneers, they dare to make unconventional decisions in line with their values and will 'walk their talk' no matter what happens. Therefore, courage is a crucial characteristic of servant leaders. Finally, being able to forgive is an invaluable quality of any human being. 
Leaders who are able to forgive, can be more open, objective and supportive of all their followers. Obviously, it is not an excuse for continuous mistakes and flaws. Forgiveness is simply about accepting the other person (Autry 2004).

Another important theoretical contribution of this study is that our data allows us to speculate on what might be primary versus secondary aspects of servant leader behavior as experienced by followers. There is clear overlap in the main findings of the factor loadings of the eight factors on the second-order servant leader factor in both confirmatory analyses (in the developmental phase), and the outcomes of second-order exploratory factor analysis that included the other servant leadership scales (Tables 4 and 5). It suggests that the primary aspects of servant leader behavior are empowerment, accountability, standing back, humility, and stewardship, leaving authenticity, courage, and forgiveness as secondary aspects. Knowing how to describe servant leader behavior as experienced by followers instead of in terms of the leader's motives or in the outcomes of leadership behavior, allows for a better recognition, operationalization and-ultimately, development of a practical instrument to encourage this kind of leadership behavior.

Since we included humility, standing back, and stewardship as essential aspects of servant leadership, this measure may also contribute to research into level-5 leadership. This type of leadership was introduced by Collins (2001) in his seminal work on successful longlasting corporations and incorporates the need for humility. However, empirical research where this is tested in the day-to-day work setting has as yet not been conducted. It is our hope that this new measure will facilitate and initiate further empirical research in this field.

\section{Limitations and Strengths}

Despite the fact that our study is quite comprehensive, we acknowledge the limitations of our study too. Our main focus was to construct a reliable and valid instrument of servant leadership, our priority was to determine the psychometric qualities of the selected items as key determinants of the eight constructs. The number of items in the SLS, especially in the first studies, prevented the inclusion of other leadership scales together with outcome measures. Therefore, to show the added value of the SLS in comparison to other leadership measures, we used a secondorder exploratory factor analysis. This gave indications of potential overlap and differences between all the leadership scales. Another limitation is that we had to rely on convenience sampling for most of the studies. Especially with web-based online studies, it is impossible to know how many people actually received the call to participate. We decided to gather data with a web-based online survey to avoid having to rely on student samples, a frequently used strategy in the development of other servant leadership measures. A resulting strength in comparison to previous measurement development articles is that with the present heterogeneous composite sample of people working in diverse professions in profit and not-for-profit sectors, mono-sample bias is avoided. This gives confidence in the generalizability of the eight-factor structure. Next, we were unable to obtain sufficient multilevel data. Most leaders and followers that were willing to participate did so anonymously. Therefore, future research should obtain data that allows the use of multilevel analysis.

It stands to reason that we are aware that our data is cross-sectional. Thus, even though we have indications that servant leadership as measured by the SLS is related to well-being and performance, it is impossible to draw firm causal conclusions about the predictive validity of the SLS. Future research should use longitudinal designs to see whether this instrument for measuring servant leader behavior is indeed able to predict follower well-being and performance over time. Nevertheless, the data presented in this article give confidence that this instrument meets the psychometric qualities to measure servant leadership from the perspective of the follower in a reliable and valid way. We would like to emphasize that when using the survey in future research, it is important to avoid changes in the wording and in the response scales, or even delete items. This may have implications for the validity of the scales as presented here.

In conclusion, with data from 2 countries, 4 studies, 8 samples, 1571 participants, and a strong link towards servant leadership theory, we have presented an instrument that is a valuable addition to the current selection of servant leadership measures. This is the first paper that includes three measures of servant leadership, allowing for a comparison between them. In order to enhance our insight into what the core of servant leadership is, studies comparing different measures are essential. Additionally, we are not aware of an article that includes this many different leadership measures and reports their interrelatedness. As such, this paper also contributes to our thinking on leadership in general. With the SLS, we now have an instrument that can be used to establish the effects of servant leadership on individuals and organizations. More and better insights grounded in empirically based findings are essential in order to alert organizations to the necessity of being open to the needs and wishes of employees, acknowledging their worth and achievements, but also of being stewards and making people feel responsible for their work. 
Acknowledgment The authors would like to thank Anna Andrejew, Marina Diepeveen, Josine Honselaar, Ngan Nguyen, and the Greenleaf Center Europe for their help with the data collection.

Open Access This article is distributed under the terms of the Creative Commons Attribution Noncommercial License which permits any noncommercial use, distribution, and reproduction in any medium, provided the original author(s) and source are credited.

\section{References}

Autry, J. A. (2004). The servant leader: How to build a creative team, develop great morale, and improve bottom-line performance. New York: Three Rivers Press.

Barbuto, J. E., Jr., \& Wheeler, D. W. (2006). Scale development and construct clarification of servant leadership. Group \& Organization Management, 31, 300-326.

Bass, B. M. (1985). Leadership and performance beyond expectations. New York: Free Press.

Bass, B. M., Avolio, B. J., Jung, D. I., \& Berson, Y. (2003). Predicting unit performance by assessing transformational and transactional leadership. Journal of Applied Psychology, 88, 207-218.

Block, P. (1993). Stewardship: Choosing service over self-interest. San Francisco: Berrett-Koehler.

Brown, M. E., Trevino, L. K., \& Harrison, D. A. (2005). Ethical leadership: A social learning perspective for construct development and testing. Organizational Behavior and Human Decision Processes, 97, 117-134.

Camman, C., Fichman, M., Jenkins, D., \& Klesh, J. (1979). The Michigan organizational assessment questionnaire. Unpublished manuscript, University of Michigan at Ann Arbor.

Cartwright, S., \& Cooper, C. L. (1994). The human effects of mergers and acquisitions. In C. L. Cooper \& D. M. Rousseau (Eds.), Trends in organizational behaviour (Vol. 1). New York: Wiley.

Clegg, S., Kornberger, M., \& Rhodes, C. (2007). Business ethics as practice. British Journal of Management, 18, 107-122.

Collins, J. (2001). Good to great: Why some companies make the leap and others don't. New York: Harper-Collins.

Conger, J. A. (1989). The charismatic leader: Behind the mystique of exceptional leadership. San Francisco: Jossey-Bass.

Conger, J. A. (2000). Motivate performance through empowerment. In E. A. Locke (Ed.), The Blackwell handbook of principles of organizational behavior (pp. 137-149). Oxford: Blackwell Publishing.

Conger, J. A., \& Kanungo, R. N. (1987). Toward a behavioral theory of charismatic leadership in organizational settings. Academy of Management Review, 12, 637-647.

Damen, F., van Knippenberg, B., \& van Knippenberg, D. (2008). Affective match: Leader emotional displays, follower positive affect, and follower performance. Journal of Applied Social Psychology, 38, 868-902.

Dannhauser, Z., \& Boshoff, A. B. (2007). Structural equivalence of the Barbuto and Wheeler (2006) Servant Leadership Questionnaire on North American and South African samples. International Journal of Leadership Studies, 2, 148-168.

Dansereau, F., Graen, G., \& Haga, W. J. (1975). A vertical dyad linkage approach to leadership within formal organizations: A longitudinal investigation of the role making process. Organizational Behavior and Human Performance, 13, 46-78.

Dennis, R. S., \& Bocarnea, M. (2005). Development of the servant leadership assessment instrument. Leadership \& Organization Development Journal, 26, 600-615.
Dennis, R., \& Winston, B. E. (2003). A factor analysis of Page and Wong's servant leadership instrument. Leadership \& Organizational Development Journal, 24, 455-459.

Ehrhart, M. G. (2004). Leadership and procedural justice climate as antecedents of unit-level organizational citizenship behavior. Personnel Psychology, 57, 61-95.

Euwema, M. C., Wendt, H., \& van Emmerik, H. (2007). Leadership styles and group organizational citizenship behavior across cultures. Journal of Organizational Behavior, 28, 1035-1057.

Fan, X., \& Sivo, S. A. (2007). Sensitivity of fit indices to model misspecification and model types. Multivariate Behavioral Research, 42, 509-529.

Ferch, S. (2005). Servant-leadership, forgiveness, and social justice. The International Journal of Servant-Leadership, 1, 97-113.

Ferguson, E., \& Cox, T. (1993). Exploratory factor analysis: A users' guide. International Journal of Selection and Assessment, 1, 84-94.

Froiland, P., Gordon, J., \& Picard, M. (1993). In search of accountability. Training, 30, 59.

Garcia-Morales, V. J., Llorens-Montes, F. J., \& Verdu-Jover, A. J. (2008). The effects of transformational leadership on organizational performance through knowledge and innovation. British Journal of Management, 19, 299-319.

George, J. M. (2000). Emotions and leadership: The role of emotional intelligence. Human Relations, 53, 1027-1055.

Graen, G. B., \& Uhl-Bien, M. (1995). Relationship-based approach to leadership. Development of leader-member exchange LMX theory. The Leadership Quarterly, 6, 219-247.

Graham, J. W. (1991). Servant-leadership in organizations: Inspirational and moral. The Leadership Quarterly, 2, 105-119.

Greenleaf, R. K. (1977). Servant-leadership: A journey into the nature of legitimate power and greatness. New York: Paulist Press.

Greenleaf, R. K. (1991). The servant as leader. Indianapolis: The Greenleaf Center.

Greenleaf, R. K. (1996). On becoming a servant leader. San Francisco: Jossey-Bass.

Greenleaf, R. K. (1998). The power of servant-leadership. San Francisco: Berrett-Koehler.

Guadagnoli, E., \& Velicer, W. (1988). Relation of sample size to the stability of component patterns. Psychological Bulletin, 103, 265-275.

Halpin, A., \& Croft, D. (1966). Organizational climate of schools. In A. Halpin (Ed.), Theory and research in administration (pp. 131-249). New York: Prentice Hall.

Harter, S. (2002). Authenticity. In C. R. Snyder \& S. J. Lopez (Eds.), Handbook of positive psychology (pp. 382-394). New York: Oxford University Press.

Hayton, J. C., Allen, D. G., \& Scarpello, V. (2004). Factor retention in exploratory factor analysis: A tutorial on parallel analysis. Organizational Research Methods, 7, 191-205.

Henson, R. K., \& Roberts, J. K. (2006). Use of exploratory factor analysis in published research. Common errors and some comment on improved practice. Educational and Psychological Measurement, 66, 393-416.

Hernandez, M. (2008). Promoting stewardship behavior in organizations: A leadership model. Journal of Business Ethics, 80, 121-128.

Hinkin, T. R. (1995). A review of scale development practices in the study of organizations. Journal of Management, 21, 967-988.

House, R. J., Hanges, P. J., Javidan, M., Dorfman, P. W., \& Gupta, V. (2004). Culture, leadership, and organizations. The Globe study of 62 societies. Thousand Oaks: Sage Publications.

Howell, J. M., \& Avolio, B. J. (1993). Transformational leadership, transactional leadership, locus of control, and support for 
innovation: Key predictors of consolidated-business-unit-performance. Journal of Applied Psychology, 78, 891-902.

Hoyt, C. L., \& Blascovich, J. (2003). Transformational and transactional leadership in virtual and physical environments. Small Group Research, 34, 678-715.

Hu, L., \& Bentler, P. M. (1998). Fit indices in covariance structure modeling: Sensitivity to underparameterized model misspecification. Psychological Methods, 3, 424-453.

Ilies, R., Morgeson, F. P., \& Nahrgang, J. D. (2005). Authentic leadership and eudaimonic well-being: Understanding leaderfollower outcomes. The Leadership Quarterly, 16, 373-394.

Konczak, L. J., Stelly, D. J., \& Trusty, M. L. (2000). Defining and measuring empowering leader behaviors: Development of an upward feedback instrument. Educational and Psychological Measurement, 60, 301-313.

Laub, J. A. (1999). Assessing the servant organization: Development of the organizational leadership assessment (OLA) instrument. Doctoral dissertation, Boca Raton, Florida.

Leary, M. R., \& Hoyle, R. H. (2009). Handbook of individual differences in social behavior. New York: The Guilford Press.

Liden, R. C., Wayne, S. J., Zhao, H., \& Henderson, D. (2008). Servant leadership: Development of a multidimensional measure and multi-level assessment. The Leadership Quarterly, 19, 161-177.

Luthans, F. (2002). The need and meaning of positive organizational behavior. Journal of Organizational Behavior, 23, 695-706.

Luthans, F., \& Avolio, B. (2003). Authentic leadership development. In K. S. Cameron \& J. E. Dutton (Eds.), Positive organizational scholarship (pp. 241-254). San Francisco: Berrett-Koehler.

McCullough, M. E., Hoyt, W. T., \& Rachal, K. C. (2000). What we know (and need to know) about assessing forgiveness constructs. In M. E. McCullough, K. I. Pargament, \& C. E. Thoresen (Eds.), Forgiveness: Theory, research, and practice (pp. 65-88). New York: Guilford Press.

McIntosh, T. A., \& Irving, J. A. (2008, May). Evaluating the Instrumento de Contribucion al Liderazgo de Siervo (ICLS) for reliability in Latin America. Paper presented at the Servant Leadership Roundtable at Regent University, Virginia Beach.

Morris, J. A., Brotheridge, C. M., \& Urbanski, J. C. (2005). Bringing humility to leadership: Antecedents and consequences of leader humility. Human Relations, 58, 1323-1350.

Morrison, E. W., \& Phelps, C. C. (1999). Taking charge at work: Extra-role efforts to initiate workplace change. Academy of Management Journal, 42, 403-419.

Mowday, R. T., Steers, R. M., \& Porter, L. W. (1979). The measurement of organizational commitment. Journal of Vocational Behavior, 14, 224-247.

Murphy, S. E., \& Ensher, E. A. (2008). A qualitative analysis of charismatic leadership in creative teams: The case of television directors. Leadership Quarterly, 19, 335-352.

Muthén, L. K., \& Muthén, B. O. (1998-2007). MPlus user's guide (5th ed.). Los Angeles: Muthén \& Muthén.

Northouse, P. G. (2007). Leadership: Theory and practice (4th ed.). Thousand Oaks, CA: Sage Publications.

Page, D., \& Wong, P. T. P. (2000). A conceptual framework to measuring servant leadership. In A. Adjibolosoo (Ed.), The human factor in shaping the course of history and development. Boston, MA: University Press of America.

Parolini, J., Patterson, K., \& Winston, B. (2009). Distinguishing between transformational and servant-leadership. Leadership \& Organization Development Journal, 30, 274-291.

Patterson, K. A. (2003). Servant leadership: A theoretical model (Doctoral dissertation, Regent University, ATT 3082719).

Peterson, C., \& Seligman, M. E. P. (2004). Character strengths and virtues: A handbook and classification. Oxford, England: Oxford University Press.
Podsakov, P. M., Todor, W. D., Grover, R. A., \& Huber, V. L. (1984). Situational moderators of leader reward and punishment behaviors: Fact or fiction? Organizational Behavior and Human Performance, 34, 21-63.

Rafferty, A. E., \& Griffin, M. A. (2004). Dimensions of transformational leadership: Conceptual and empirical extensions. The Leadership Quarterly, 15, 329-354.

Reinke, S. J. (2004). Service before self: Towards a theory of servantleadership. Global Virtue Ethics Review, 3, 30-57.

Russell, R. F., \& Stone, A. G. (2002). A review of servant-leadership attributes: Developing a practical model. Leadership \& Organization Development Journal, 23, 145-157.

Ryan, R. M., \& Frederick, C. (1997). On energy, personality, and health: Subjective vitality as a dynamic reflection of well-being. Journal of Personality, 65, 529-565.

Scandura, T., \& Graen, G. B. (1984). Moderating effects of initial leader-member exchange status on the effects of a leadership intervention. Journal of Applied Psychology, 69, 428-436.

Schaufeli, W. B., Salanova, M., González-Romá, V., \& Bakker, A. B. (2002). The measurement of burnout and engagement: A confirmatory factor analytic approach. Journal of Happiness Studies, 3, 71-92.

Sendjaya, S., Sarros, J. C., \& Santora, J. C. (2008). Defining and measuring servant-leadership behaviour in organizations. Journal of Management Studies, 45, 402-424.

Shamir, B., House, R. J., \& Arthur, M. B. (1993). The motivational aspects of charismatic leadership: A self-concept theory. Organizational Science, 4, 1-17.

Shamir, B., \& Howell, J. M. (1999). Organizational and contextual influences on the emergence and effectiveness of charismatic leadership. The Leadership Quarterly, 10, 257-283.

Sosik, J. J., \& Godshalk, V. M. (2000). Leadership, mentoring functions received, and job-related stress: A conceptual model and preliminary study. Journal of Organizational Behavior, 21, 365-390.

Spears, L. C. (1995). Reflections on leadership: How Robert K. Greenleaf's theory of servant-leadership influenced today's top management thinkers. New York: Wiley.

Stone, A. G., Russell, R. F., \& Patterson, K. (2004). Transformational versus servant-leadership: A difference in leader focus. Leadership \& Organizational Development Journal, 25, 349-361.

Van Dierendonck, D., Haynes, C., Borrill, C., \& Stride, C. (2004). Leadership behavior and subordinate well-being. Journal of Occupational Health Psychology, 9, 165-175.

Van Dierendonck, D., \& Heeren, I. (2006). Toward a research model of servant-leadership. The International Journal of ServantLeadership, 2, 147-169.

Venkatraman, N. (1989). Strategic orientation of business enterprises: The construct, dimensionality, and measurement. Management Science, 35, 942-962.

Walter, F., \& Bruch, H. (2008). The positive group affect spiral: A dynamic model of the emergence of positive affective similarity in work groups. Journal of Organizational Behavior, 29, 239-261.

West, M. A., Borrill, C. S., Dawson, J. F., Brodbeck, F., Shapiro, D. A., \& Haward, B. (2003). Leadership clarity and team innovation in health care. Leadership Quarterly, 14, 393-410.

Williamson, T. (2008). The good society and the good soul: Plato's Republic on leadership. The Leadership Quarterly, 19, 397-408.

Wong, P. T. P., \& Davey, D. (2007). Best practices in servant leadership. Servant leadership research roundtable_July 2007. Virginia Beach: Regent University. 